\title{
A model for predicting organic compounds concentration change in water associated with horizontal hydraulic fracturing
}

\author{
Lanting Ma ${ }^{\mathrm{a}, *}$, Antonio Hurtado ${ }^{\mathrm{b}}$, Sonsoles Eguilior ${ }^{\mathrm{b}}$, Juan F. Llamas Borrajo ${ }^{\mathrm{a}}$ \\ a Escuela Técnica Superior de Ingenieros de Minas y Energía de Madrid, Calle de Ríos Rosas 21, 28003 Madrid, Spain \\ ${ }^{\mathrm{b}}$ Centro de Investigaciones Energéticas, Medioambientales y Tecnológicas, Avda. Complutense 40, Edif. 20, 28040 Madrid, Spain
}

\section{A B S T R A C T}

Horizontal drilling and hydraulic fracturing are technologies designed to increase natural gas flow and to improve productivity in low permeability formations. During this drilling operation, tons of flowback and produced water. which contain several organic compounds, return to the surface with a potential risk of influencing the surrounding environment and human health. In order to conduct predictive risk assessments a mathematical model is needed to evaluate organic compound behaviour along the water transportation process as well as concentration changes over time throughout the operational life cycle. A comprehensive model, which fits the experimental data, combining an Organic Matter Transport Dynamic Model with a Two-Compartment First-order Rate Constant (TFRC) Model has been established to quantify the organic compounds concentrations. This algorithm model incorporates two transportation rates, fast and slow. The results show that the higher the value of the organic carbon partition coefficient $\left(k_{o c}\right)$ in chemicals, the later the maximum concentration in water will be reached. The maximum concentration percentage would reach up to $90 \%$ of the available concentration of each compound in shale formation (whose origin may be associated to drilling fluid, connate water and/or rock matrix) over a sufficiently long period of time. This model could serve as a contribution to enhance monitoring strategy, increase benefits out of optimizing health risk assessment for local residents and provide initial baseline data to further operations.

\section{Introduction}

Unconventional natural gas in shale deposits has become one of the most rapidly expanding trends in global onshore petroleum exploration 
and development (Tan, 2014). Hydraulic fracturing technology is employed for oil and gas production due to low permeability and the need to increase flow rates, linked to the fact that the rock in a shale formation is typically easily breakable (Jackson et al., 2013a; Suárez, 2012). Millions of gallons of water, thousands of gallons of chemicals, and suspended solids are injected into the target formation under high pressure to create cracks to increase the amount of releasable hydrocarbons contained in the target formation. After injection, gas, oil, salt water and hydraulic fracturing fluids flow as the generated propped fractures are kept open and provide permeability to allow the mobility of fluids. Although the range is very variable, it is possible to say that it is expected that between ten and thirty percent of the injected fluid will return to the surface (Balaba and Smart, 2012). Environmental hazards associated with this hydraulic fracturing released wastewater have raised concerns about potential impacts on health (Elliott et al., 2016; Vengosh et al., 2014; Jiang et al., 2014).

Shale gas wells are projected to have a lifetime of 30 or more years (Kondash et al., 2017) and production waters will flow back along with the gas to the surface during the whole wells life cycle. In the existing studies about production waters, which span even beyond years in different geological formations (see, for example, Kondash et al., 2017) it is clear that these wastewater volumes exhibit a behaviour with high flow rates in the first few months, followed by a slow drop of production in subsequent months to years. Production waters are divided into produced and flowback water depending on the amount of time elapsed since the hydraulic fracturing. Flowback water consists mainly of the fluid used to perform hydraulic fracturing where the formation water fraction is gradually increased. The injected hydraulic fracturing water rate varies between $80 \%$ in day 1 and $30 \%$ day 30 with a contribution of the naturally occurring brine component in the blend mean of $\sim 85 \%$ after 60 days following hydraulic fracturing (Kondash et al., 2017). Thus, in this water, that generally occurs over 3 to 4 weeks after water injection, the chemistry of the injection water predominates, although it also contains a variable set of chemical compounds that come from the formation water (Stewart, 2015). Its final content is, therefore, a function of both the injection fluid and the formation water, both widely variable. On the other hand, produced water has higher natural formation water content, tend to become increasingly saline. It returns at a lower rate but with high levels of organic and inorganic compounds that reflect the chemistry of the formation fluids (Vengosh et al., 2014; Jiang et al., 2014) as well as the target natural gas (mostly methane plus propane, butane, and ethane). Therefore production waters from horizontal fractured wells contains not only additive compounds such as surfactants, gel, corrosion inhibitors, etc., but also other gases such as carbon dioxide, hydrogen sulphide, nitrogen and helium; formation brine including total dissolved solids (TDS) and trace elements as mercury, arsenic or lead; naturally occurring radioactive material (NORM); organic constituents and volatile organic compounds, for instance benzene among others (Bloomdahl et al., 2014; King, 2012). Proper disposal of wastewater fluids is critically important to the protection of both surface and ground water (Krupnick and Gordon, 2015). In standardized wastewater treatment it is stored in holding tanks or often in lined or unlined above-ground pit containers (Hoffman et al., 2014) to be later reused afterwards, deep well injection disposal or treated for release (Yost et al., 2016). In the context of an adequate management of these fluids, the predictive estimation of their composition as well as their temporal evolution are very useful tools in the decision making process. In this line of reasoning, modelling the flowback behaviour provides indispensable scientific knowledge and has undeniable benefits in optimizing well production operations (Gdanski et al., 2010).

Potential environmental toxicity and water quality pollution impacts of flowback, and produced water will depend on toxic pollutant concentrations (Jiang et al., 2014) in above-ground pit containers. This aspect is of particular interest since in 2013, Resources for the Future (RFF) released the results of a study of four key stakeholder groups in shale gas development-industry, regulators, nongovernmental organizations (NGOs), and academics (Krupnick et al., 2013). In this survey, the risk pathway (linking routine shale gas development activities to the burdens that impact the environment and local communities) that was most often selected by the stakeholder groups was on-site pit storage of flowback and produced water constituents and the potential for leakage into surface water (Kuwayama et al., 2015). In addition to concerns regarding surface water, the risk to groundwater resources generated by on-site pit storage of flowback and produced water constituents was also a pathway that was common to all groups' top 10 most selected pathways (Krupnick and Gordon, 2015).

In order to reduce the high associated uncertainties to organic chemical concentrations (Jiang et al., 2014) and to be able to carry out an inventory of the masses and concentrations present in holding tanks a model that allows estimating the time evolution of the concentration of pollutants in flowback and produced waters is necessary. This model together with the expected water volumes throughout the life of a production well (Kondash et al., 2017) will allow adjusting the amount of contaminants present in the above-ground pit containers over time and make a more accurate estimate of their potential environmental toxicity. Almost $77 \%$ wetland and $13 \%$ river will exposed in high risk situation (Meng, 2015) related to the surrounding water system contamination when disposal water leaks or improper disposal operations take place (U.S. EPA, 2015; Osborn et al., 2011; Warner et al., 2013; Vidic et al., 2013).

The current research on environmental and human health impact derived from fracturing and drilling activities has already embarked on monitoring surrounding water indicators (Molofsky et al., 2013; Kravchenko et al., 2014) analysing whether contaminants concentration in samples exceed the limits imposed by the authorities (Bunch et al., 2014) and providing forward opinions on treatment (Rahm et al., 2013). However, the current state of knowledge is determined by the following constraining factors: (1) unconventional hydraulic fracturing of shale formation for extraction of shale gas has only expanded to Canada, USA and a few other countries (Vengosh et al., 2014) with a relative small number of flowback and produced water sample analysis available given the total number of wells in operation; (2) lack of specific, long-term and systematic monitoring of the nearby environment (Struchtemeyer et al., 2012), to understand critical macro or micro elements influence of fracturing operations; (3) a large amount of published literature on organic compounds present in produced water informing about risk to residents (McKenzie et al., 2012; Bloomdahl et al., 2014), but a lack of data needed to develop more accurate epidemiological studies and (4) an important source of controversy on the possibility of water contamination due to the possibility that local geophysical experiments cannot provide sufficient information for an assessment. All of the above underlines the need to have predictive estimation models to: 1 ) evaluate the quantity of the various pollutants that could travel to the surface or proximal areas and generate pollution; and 2) establish the relationships between the initial and flowback concentration for any given day for each compound or families of compounds.

Therefore, the purpose of this study is to provide a model that could forecast almost all-realistic organic chemical concentration trends in wastewater over time to prevent the hazards occur. Being able to anticipate the expected chemical composition over time in produced and flowback water is an important step toward an appropriate safety and risk assessment. This work will allow us to identify and/or develop adequate treatments for these wastes and to predict the health and environmental risks derived from accidents and exposures. This assessment study procedure is as follows: (1) reassembling a new comprehensive model resulting from previous studies on organic chemical transport dynamics and a first-order desorption kinetics model, (2) utilizing published Volatile Organic Compounds (VOCs) and SemiVOCs concentration data to verify and test our model, and (3) estimating prospective concentration ratio range tendency in produced water for a 
long time period (10 years). Environmental hazards and potential toxicity in residents have a close link with chemicals doses and exposure time to contaminated areas. Thus risk management should be analysed throughout the whole operation period. This is the reason why concentration forecast is considered to be a crucial data. All in all, this model could serve as a contribution to increase the benefits of optimizing health risk assessment for local residents and to provide experience to further operations, as well as to define and adjust the monitoring aspects in flowback and produced water.

\section{Methods}

A simplified geometrical model of the hydrofractures in the rock matrix will be used for the a priori determination of the mathematical model to fit the temporal evolution of the concentrations of experimentally observed organic compounds (Hayes, 2009). The physical processes involved in the fluids movement present in the geological formation will be applied on this model. For fitting and validation of the model this work uses data released by the Marcellus Shale Coalition (Hayes database) in a report of the Gas Technology Institute (Hayes, 2009).

\subsection{Hydraulic fracturing model setup}

After a horizontal section is drilled through the target shale layer, rock in shale formation was fractured by means of a pressurized liquid and the cracks provide an avenue for natural gas, petroleum and brine to more quickly return to the surface (Gandossi, 2013). This report's approach of the average behaviour of an hydraulic fracturing is a model based on previous works that describe both the network generation (Jackson et al., 2013b) as a mathematical representation and the parameters associated with it (Balashov et al., 2015) which have been considered within the scope of this work as both involve the same formations.

The horizontal hydraulic fracturing shale gas model is shown in Fig. 1a (Jackson et al., 2013b) with the fracturing process illustrated in Fig. 1b (Jackson et al., 2013b). The model assumes a horizontal well length of $1500 \mathrm{~m}(\approx 5000 \mathrm{ft}$.) divided into 10 equal parts (Jurus et al., 2013).

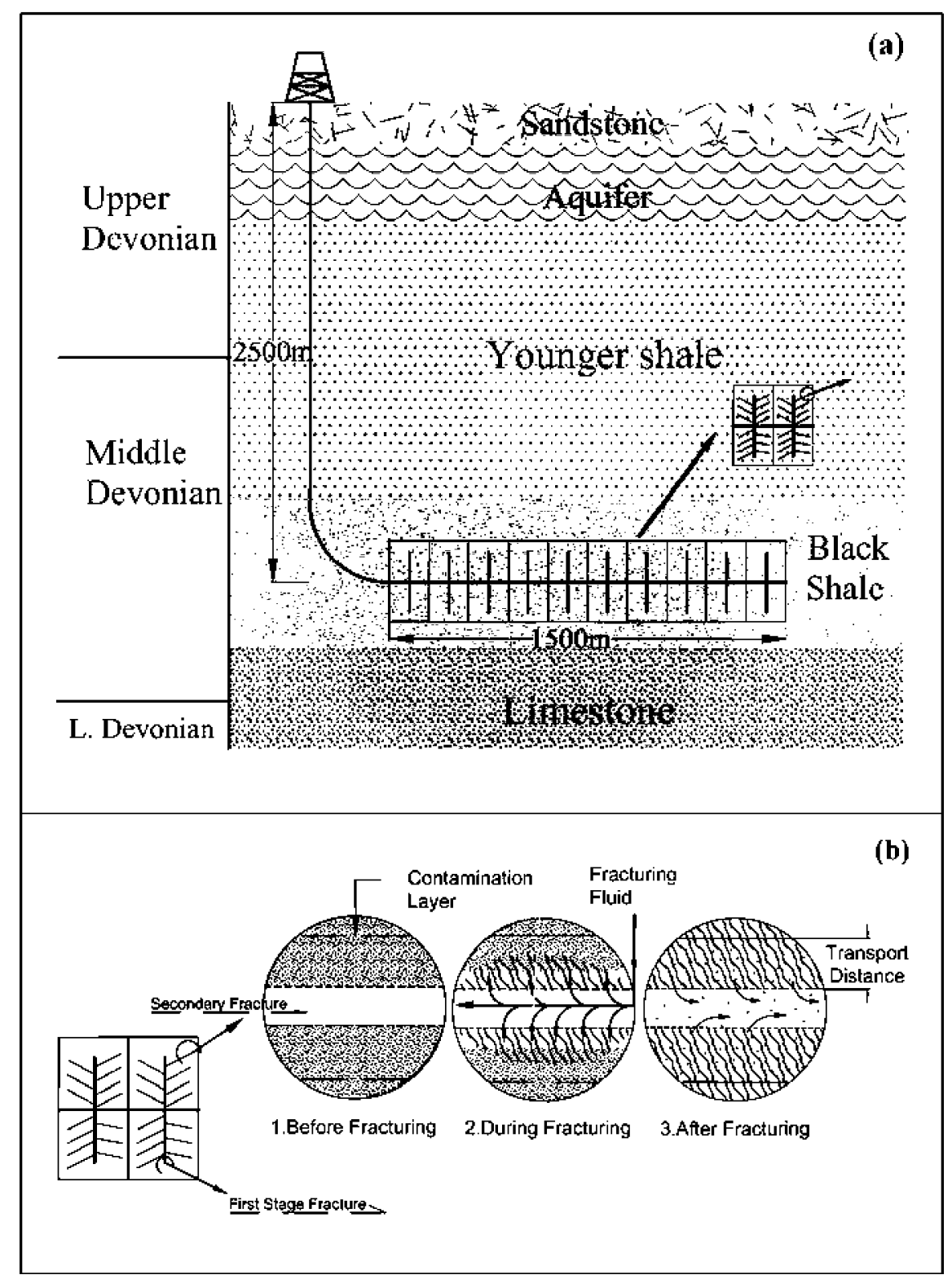

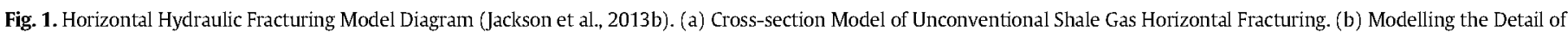
Hydraulic Fracturing Process. 
Studies carried out based in the model displayed in Fig. 1a (Jackson et al., 2013b), assuming as reasonable value 1 secondary fracture per $6 \mathrm{~m}$ (19.68 ft) length (Balashov et al., 2015), the average chemicals (in all phases) transmission distance $x$ equalled $3 \mathrm{~m}(9.8 \mathrm{ft})$. Therefore, the simplified model, displayed in Fig. 1b, presumes there was a constant contaminant concentration layer $3 \mathrm{~m}(9.8 \mathrm{ft})$ away from the secondary fracture. After the fracturing operation, the contamination would flow with hydraulic fluid to the fractures. It's assumed that the hydraulic conductivity did not change with time.

Local Geophysical Parameters in the Marcellus Shale as the bulk particle density, the partition of organic matter in soil matter and the hydraulic gradient are shown in Table 1. Also effective upscale transport parameters, such as effective diffusivity and hydraulic conductivity, used to extrapolate pore scale processes up to the continuum scale, are displayed in the Table 1.

\subsection{Mathematical model}

For the study of the chemical composition of flowback and produced waters it will be necessary to construct and solve a mathematical model for the transport of pollutants in an aqueous phase from the rock matrix to the fractures generated. The different processes physical, chemical and biological should be considered.

As Balashov's previous research has proven (Balashov et al., 2015), the physical mechanism that described the process by which inorganic chemicals present in the pore fluid from Marcellus Shale matrix are diffused into flowback or production waters can be approached as the case of diffusion between a limited stirred volume (the hydraulic fracturing water) and a solid layer of infinite thickness (the shale matrix). This approximation was valid to describe the experimental salinity results and how the brine salt from shale could explain the salinity of the produced water (Balashov et al., 2015). In the present case we are going to maintain the same geometry for the transport model, that is, a set of parallel aperture fractures $w$ and separated by a distance $h$, filled at time $t=0$ by the fracturing fluid. Under these conditions, the hypothesis of the organic compounds transport from location to fractures was primarily onedimensional. Furthermore, the concentration in the shale matrix zone has been considered constant. A steady uniform flow field was imposed and the effects of dispersion were considered spatially constant.

The starting point for the transport study of solutes is the macroscopic mass balance equation for a component. The total flux is made up of the sum of advective, convective and dispersive flux. In addition, the continuous variation of the components concentration is affected by various sources and sinks within the domain of interest (i.e. chemical reactions). There has not been introduced the effects of biodegradation because these are not great enough to bring about a change in the behaviour of the system given the objectives of this research (Shan and Stephens, 1995). Indeed, although the general transport equation may include a biodegradation term, which in the first approximation may

Table 1

Local Geophysical Parameters in the Marcellus Shale

\begin{tabular}{lll}
\hline Parameter & Coefficient & Reference \\
\hline Effective particle porosity of & $\mathrm{ND}^{\mathrm{a}}(0.02,0.01$, & (Balashov et al., 2015) \\
sample $\left(\varphi_{e}\right)$ & $0.01,0.1)$ & \\
Diffusion coefficient of porous & $\mathrm{ND}^{\mathrm{a}}(6.34 \mathrm{E}-9,1 \mathrm{E}-9$, & (Balashov et al., 2015) \\
media $\left(D_{0}, \mathrm{~m}^{2} \mathrm{~s}^{-1}\right)$ & $3 \mathrm{E}-9,9 \mathrm{E}-9)$ & \\
Average particle size $(l, \mathrm{~m})$ & $\mathrm{ND}^{\mathrm{a}}(0.0003$, & (He, Wang, Liu, Barbot, \\
& $0.0001,0,0.1)$ & and Vidic, 2014) \\
Bulk particle density $\left(\rho, \mathrm{kg} / \mathrm{m}^{3}\right)$ & $\mathrm{ND}^{\mathrm{a}}(2.5,0.1,0,4)$ & (Manger, 1963) \\
Partition of organic matter in soil & $\mathrm{ND}^{\mathrm{a}}(0.05,0.005,0$, & (Birdwell et al., 2007) \\
matter $\left(f_{o c}\right)$ & $1)$ & \\
Soil Organic Carbon-Water & Depend on & https://rais.ornl.gov/ \\
Partitioning Coefficient $\left(k_{o c}\right)$ & compounds & \\
& properties & \\
\hline
\end{tabular}

${ }^{a}$ ND - normal distribution function (mean, standard deviation, minimum, and maximum) be described in terms of first-order reactions wherein the transformation rate is proportional to the solute concentration (Runkel, 1996), this process has been excluded as a result of studies conducted with the production waters that do not indicate an abundance of microbes (Akob et al., 2015) so the biodegradation is expected to be small in shales (Schlegel et al., 2013). Yet the goal of the study is placed within the context of risk management, from this point of view the nonconsideration of this term introduces bias in a rational and feasible manner faced to improve safety. That is to say, an upper limit to the concentrations is being obtained within the limitations defined by the conservative risk regulations (Viscusi et al., 1997).

According to these assumptions, the organic contaminate transportation equation was established with constant process parameters for convection, diffusion, dispersion, adsorption retention and desorption (Runkel, 1996):

$$
\left.\begin{array}{l}
R_{d} \frac{\partial C}{\partial t}=\left(D_{1}+D_{2}\right) \cdot \frac{\partial^{2} C}{\partial x^{2}}-v \frac{\partial C}{\partial x}-k \cdot R_{d} \cdot C \\
C(x, 0)=0, x>0 \\
C(0, t)=C_{0}, t=0 \\
C(\infty, 0)=0, t \geq 0
\end{array}\right\}
$$

where $C$ is the concentration in mass per unit volume of solution [mass $\cdot$ length ${ }^{-3}$ ]; $v$ is the average groundwater velocity in the direction of flow [length- time ${ }^{-1}$ ]; $D_{1}$ is the coefficient of molecular diffusion of the element in the fluid phase [length ${ }^{2} \cdot$ time $^{-1}$ ]; $D_{2}$ is the coefficient of mechanical (or convective) dispersion [length ${ }^{2} \cdot$ time $^{-1}$ ]; $k$ is the desorption first order rate constant [time ${ }^{-1}$ ]; $R_{d}$ is the retention factor; $t$ is the time coordinate [time] and $x$ is the space coordinate [length].

Dividing both sides of the retention factor $R_{d}$ in Eq. 1, we obtained the following expression:

$\frac{\partial C}{\partial t}=\frac{D}{R_{d}} \cdot \frac{\partial^{2} C}{\partial x^{2}}-\frac{v}{R_{d}} \cdot \frac{\partial C}{\partial x}-k \cdot C$

where $D=D_{1}+D_{2}$ is the coefficient of hydrodynamic dispersion [length ${ }^{2}$ time $^{-1}$ ] and $k$ is the desorption first order rate constant [time $\left.{ }^{-1}\right]$.

Generally, the desorption part is described by an isotherm equation, $C=C_{0} \exp (-k \cdot t)$. This expression is not dependent on spatial coordinate, thus a parameter $C_{1}$ has been introduced.

$C=C_{1} \cdot \exp (-k \cdot t)$

So, Eq. 3 could be rewritten as:

$\frac{\partial C_{1}}{\partial t}=\frac{D}{R_{d}} \cdot \frac{\partial^{2} C_{1}}{\partial x^{2}}-\frac{v}{R_{d}} \cdot \frac{\partial C_{1}}{\partial x}$

with $C_{1}$ - Concentration without considering desorption activity.

After Laplace transformation, the analytic solution for $C_{1}$ was given by (Sauty, 1980).

$C_{1}(x, t)=\frac{C_{0}}{2} \cdot\left\{\operatorname{erfc}\left[\frac{x-\left(v / R_{d}\right) \cdot t}{2 \sqrt{\left(D / R_{d}\right) \cdot t}}\right]+\exp \left[\frac{\left(v / R_{d}\right) \cdot x}{\left(D / R_{d}\right)}\right] \cdot \operatorname{erfc}\left[\frac{x+\left(v / R_{d}\right) \cdot t}{2 \cdot \sqrt{\left(D / R_{d}\right) \cdot t}}\right]\right\}$

where $C_{O}$ is the initial concentration. 
Therefore, combining Eqs. 4 and 6 yields the analytical solution for this model:

$$
\begin{aligned}
C=C_{1}(x, t) & \cdot \exp (-k \cdot t)==\frac{C_{0}}{2} \cdot\left\{\operatorname{erfc}\left[\frac{x-\left(v / R_{d}\right) \cdot t}{2 \sqrt{\left(D / R_{d}\right) \cdot t}}\right]\right. \\
+ & \left.\exp \left[\frac{\left(v / R_{d}\right) \cdot x}{\left(D / R_{d}\right)}\right] \cdot \operatorname{erfc}\left[\frac{x+\left(v / R_{d}\right) \cdot t}{2 \cdot \sqrt{\left(D / R_{d}\right) \cdot t}}\right]\right\} \times \exp (-k \cdot t)
\end{aligned}
$$

The desorption phenomenon (term exp. $(-k \cdot t)$ in Eq. 7) constitutes the source term of polluting substances and is produced from shale bituminous rock to fractures by which water flows. It is a process that may have subsequent effects on the toxicity and associated hazard to human and aquatic life when these pollutants are transported to the surface in the flowback and produced waters. Therefore, it is important that desorption of contaminants from the rock matrix is properly explained in order to evaluate the potential risk of shale gas projects.

Expression 7 can be simplified by taking into account a series of assumptions which will be detailed below:

- Average transportation distance for all chemicals analysed was $3 \mathrm{~m}$ as shown in Fig. 1b. This spacing of hydrofractures is consistent with the results indicated in Balashov, where for usual hydrofracking values the fracture aperture varies between tenths of millimetres and millimetres and the spacing varies between 0.2 and $5 \mathrm{~m}(0.7$ and $16 \mathrm{ft}$ ) (Balashov et al., 2015);

- $\alpha \cdot v>>D_{a q}$ ( $\alpha$ was characterization of dispersion and it can be calculated as $\alpha=0.83 \cdot(\log x)^{2.414}($ Neuman, 1990)),

- therefore $D_{a q}$ value can be eliminated and the parameter $D$ can be represented by the velocity as:

$\frac{D}{R_{d}}=\frac{\alpha \cdot v+D_{a q}}{R_{d}}=\frac{0.83(\log x)^{2.414} \cdot v+D_{a q}}{R_{d}} \approx \frac{0.14 v}{R_{d}}$

Due to the Peclet number in our model $P e=v \cdot x / D>200$, the error when the second addend is removal in Eq. 7 is less than $4 \%$. Therefore this part of the Expression (7) can be ignored (Bear and Verruijt, 1987) and the transport equation is simplify to:

$C(t)=\frac{C_{0}}{2} \cdot \operatorname{erfc}\left[\frac{4}{\sqrt{\left(v / R_{d}\right) \cdot t}}-1.34 \sqrt{\left(v / R_{d}\right) \cdot t}\right] \times \exp (-k \cdot t)$

where $C(t)$ is the pollutant concentration in the water in time $t ; C_{0}$ is the initial concentration available in the rock medium, i.e., that can be desorbed; $v$ is the velocity of the fluid; $R_{d}$, the coefficient of delay; and $k$, the desorption constant.

When the Expression (9) obtained by such simplifications adequately describes the physics in the medium, an inverse fitting with the experimental data can be performed and high coefficients of goodnessof-fit of the data are obtained. The required parameters to calculate with the least squares fitting method are: $C_{0}, v / R_{d}$ and $k$. To validate the model, the BTEX concentrations (Benzene, Toluene, Xylene and Ethylbenzene) corresponding to well $F$ of the Hayes database (Hayes, 2009) have been used. The fitting made can be seen in Fig. 2. Both the figure and the statistics associated with the fitting (see Table 2) indicate that the experimental data from Hayes database cannot be well fitted with the simple first-order kinetics model used in Eq. 9.

Adjustments show that either 90 day data dominate (toluene, $x y$ lene), with adjustments that do not work well during the first 14 days, or that day 90 is not properly adjusted (Benzene). However, if the Eq. 9 is used to fit only the first 14th days data, a proper fitting is obtained (see Fig. 3).

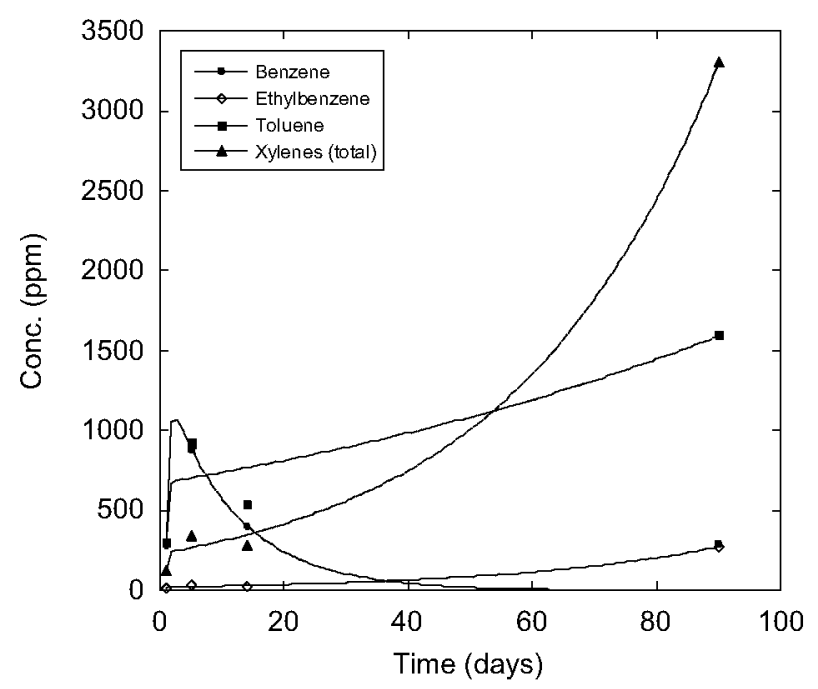

Fig. 2. Fittings for Well F with the model given by Eq. 9.

In order to be able to estimate the errors present in the determination of the predictive values obtained with the application of the model with respect to the experimental values, three criteria have been used: coefficient of determination (Pearson's $R$ (Mean Squared Error)), Nash-Sutcliffe efficiency $E$ (Nash and Sutcliffe, 1970) and index of agreement $d$ (Willmot, 1981). The differences in the values of the criteria used to measure the goodness-of-fit (see Table 2) show that the data associated with the first 14 days can be grouped and described with a constant of desorption. However, it can also be inferred from the used criteria that it is not possible to fit the data for the 90th day at the same time.

These results indicate that the model is not complete and that show that a new desorption model had to be adopted in order to can adequately explain the concentrations evolution.

Different models have been developed to explain desorption kinetics. Unfortunately, even though a large amount of mechanistic laboratory research has been directed toward understanding and quantifying the fate of hydrophobic chemicals in contact with naturally occurring particles in the water column, the ability to predict their fate is still quite poor (Kan et al., 2000). There are several factors that control desorption processes and the relative extent of desorption such as swelling of the sediment organic matter, the characteristics of mineral surfaces, or the micropore size in the geosorbents (Elhaddad, 2012).

Table 2

Fitting criteria corresponding to the data from all the sampled days $(0,1,5,14$ and 90$)$ and with the data corresponding to the flowback water (days $0,1,5$ and 14). In the case of the fitting with all the data, the obtained values for the first 14 days are also shown, since in some of the cases the 90th day values are of a significantly greater magnitude.

\begin{tabular}{llllll}
\hline & Fitting & $\begin{array}{l}\text { Adjusting index } \\
\text { obtained for days }\end{array}$ & $\begin{array}{l}\text { Nash-Sutcliffe } \\
\text { efficiency } \\
(E)\end{array}$ & $\begin{array}{l}\text { Index of } \\
\text { agreement } \\
(d)\end{array}$ & $\begin{array}{l}\text { Pearson's } \\
R\end{array}$ \\
\hline Benzene & Fig. 2 & All $^{\mathrm{a}}$ & 0.653 & 0.933 & 0.932 \\
& & Flowback $^{\mathrm{b}}$ & 0.999 & 0.999 & 0.999 \\
& Fig. 3 & Flowback $^{\mathrm{b}}$ & 1.000 & 1.000 & 1.000 \\
Ethylbenzene & Fig. 2 & All $^{\mathrm{a}}$ & 0.998 & 0.999 & 0.999 \\
& & Flowback $^{\mathrm{b}}$ & 0.667 & 0.908 & 0.832 \\
Toluene & Fig. 3 & Flowback $^{\mathrm{b}}$ & 1.000 & 1.000 & 1.000 \\
& Fig. 2 & All $^{\mathrm{a}}$ & 0.898 & 0.973 & 0.948 \\
& & Flowback $^{\mathrm{b}}$ & 0.497 & 0.830 & 0.711 \\
Xylenes & Fig. 3 & Flowback $^{\mathrm{b}}$ & 1.000 & 1.000 & 1.000 \\
& Fig. 2 & All $^{\mathrm{a}}$ & 0.998 & 0.999 & 0.999 \\
& & Flowback $^{(\mathrm{b})}$ & 0.614 & 0.893 & 0.808 \\
& Fig. 3 & Flowback $^{(\mathrm{b})}$ & 1.000 & 1.000 & 1.000 \\
\hline
\end{tabular}

a All data: days $0,1,5,14$ and 90 .

b Flowback data: days 0, 1,5 and 14. 


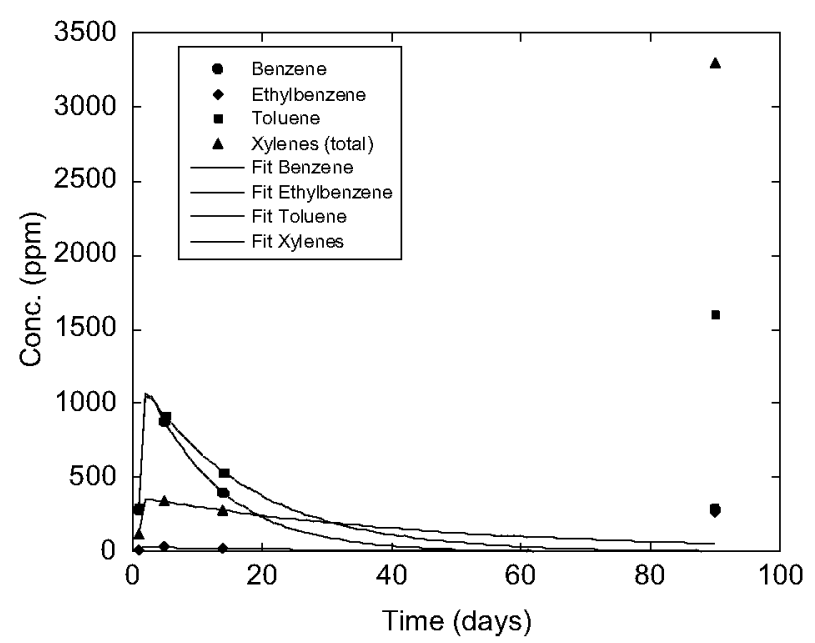

Fig. 3. Fittings for Well $\mathrm{F}$ with the model given by Eq. 9 without data corresponding to day 90.

One of the empirical algorithms more commonly used to fit data and obtain release rate parameters is the Two-compartment First-order Rate Constant (TFRC) kinetic model by Cornelissen et al. (1997); Birdwell et al. (2007) and Barnier et al. (2014). This empirical method is based on the observation of biphasic desorption and the observed shape of desorption profiles. Its usability is justified by the fact that the detailed mechanistic understanding of slow desorption rate is not yet available. So this TFRC model was chosen (Eq. 10), with each compartment defined by its respective rate constant (Barnier et al., 2014).

$C_{t}=C_{0} \cdot\left[\exp \left(-k_{\text {fast }} \cdot t\right)+\varphi \cdot \exp \left(-k_{\text {slow }} \cdot t\right)\right]$

where $C_{t}$ is the liquid phase chemical concentration at some time after $t$ $=0$ [contaminant-mass-sorbent-mass $\left.{ }^{-1}\right] ; C_{0}$ is the solid-phase concentration prior to desorption; $\phi$ is the fraction of the total slow desorbing chemical present; and $k_{\text {fast }}$ and $k_{\text {slow }}$ are the first-order rate constants describing the release rates for the fast and slow desorbing chemical, respectively [time ${ }^{-1}$ ].

Therefore, in Eq. 9 the decreasing exponential term, which represents the desorption part, was replaced by TFRC. The final model is given by Eq. 11:

$$
\begin{aligned}
& C=\frac{C_{0}}{2} \cdot \operatorname{erfc}\left[\frac{4}{\sqrt{\left(v / R_{d}\right) \cdot t}}-1.34 \cdot \sqrt{\left(v / R_{d}\right) \cdot t}\right] \\
& \times\left[\exp \left(-k_{\text {fast }} \cdot t\right)+\varphi \cdot \exp \left(-k_{\text {slow }} \cdot t\right)\right] \\
& C_{t_{-} \text {fast }}= \frac{C_{0 \_ \text {fast }}}{2} \cdot \operatorname{erfc}\left[\frac{4}{\sqrt{\left(v / R_{d}\right) \cdot t}}-1.34 \sqrt{\left(v / R_{d}\right) \cdot t}\right] \\
& \times \exp \left(-k_{\text {fast }} \cdot t\right) \\
& C_{t_{-} \text {slow }}= \frac{C_{0 \_ \text {slow }}}{2} \cdot \operatorname{erfc}\left[\frac{4}{\sqrt{\left(v / R_{d}\right) \cdot t}}-1.34 \sqrt{\left(v / R_{d}\right) \cdot t}\right] \\
& \times \exp \left(-k_{\text {slow }} \cdot t\right)
\end{aligned}
$$

where $C_{t \text { fast }}$ and $C_{t_{-} \text {slow }}$ are the expressions for fast and slow chemical transport and $C_{O_{-} \text {fast }} / C_{O_{-} \text {slow }}$ represents the initial chemical concentration present in the shale formation that is available for fast/slow desorption. So, the transportation process for organic chemicals is dependent on two parameters $-k_{\text {fast }}$ and $k_{\text {slow }}$. The initial fast release occurs during the first few days after fracturing and it is followed by a slower stage which can take months or years (Birdwell et al., 2007).

Fig. 4 shows that this model allows fit all the experimental points for the different measurement days. The Nash-Sutcliffe efficiency $E$ (NSE) exceeds in all cases the value of 0.99 , as it happens with the rest of the

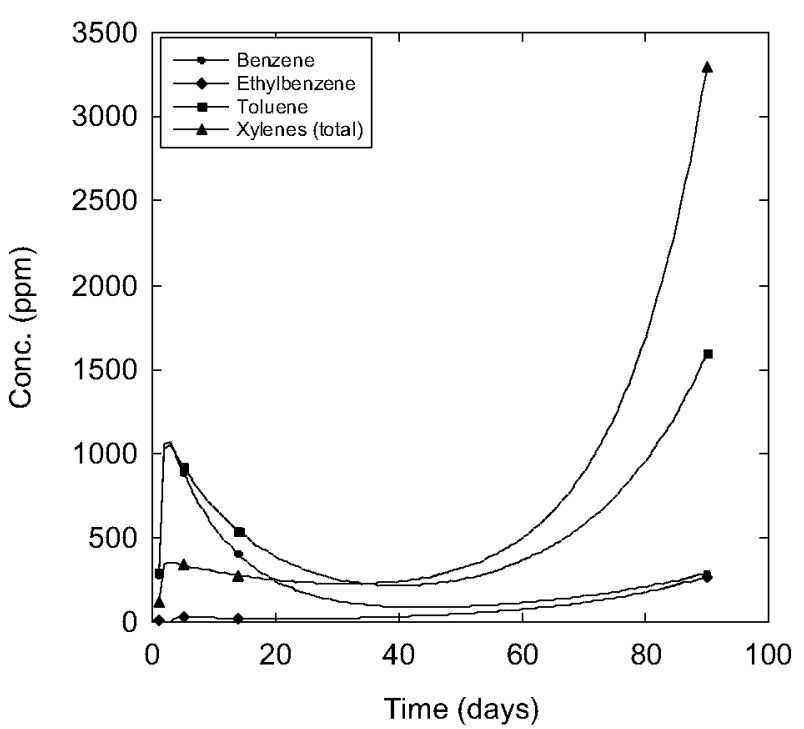

Fig. 4. Fitting for Well $\mathrm{F}$ with the desorption model of Two Compartments First-order Rate Constants (model given by Eq. 11).

criteria applied, the index of agreement $d$ and the Pearson's $R$. But, given the number of parameters to adjust involve in Eq. 11, and the small amount of temporal data available the values of the fitting parameters are not unique. This forces us to separate the posterior analysis into two blocks, one with the flowback data (first 14th days) and another with the data corresponding to day 90 .

\section{Model application to VOCs and SVOCs. Results and discussion}

Direct discharge of oil and gas produced water is prohibited by federal law (EPA, 2013) but Jiang developed this case to assess the maximum potential toxicity of Marcellus shale flowback and produced water. It is also used to identify the chemical species in flowback and produced water with the largest environmental toxicity, enabling improved design of wastewater treatment. With this scenario the potential toxicity of the chemicals in the wastewater from the well site in Marcellus exceeds those associated with supply chain production, except for carcinogenic effects. (Jiang et al., 2014). This scenario is very unlikely but wastewater leaks are the most probably pollution causes in Marcellus shale gas and in general shale gas industry (Davies et al., 2014). In addition, the organic compounds are brought above ground in the fracking flowback or produced water, which often are put into open impoundments (frack ponds), where the waste water releases its organic compounds into the air. $37 \%$ of the chemicals used during fracturing and natural gas production have been found to be volatile and be airborne. $71 \%$ of the volatile chemicals can harm the cardiovascular system and blood, $66 \%$ can harm the kidneys, and the chances of exposures to volatile chemicals are significantly increased when they are inhaled by humans or are even taken in and absorbed through the skin (Colborn et al., 2011; Meng, 2015). The flowback and produced water analysis show that more than 212 organic compound are presented (Hayes, 2009). The chemical composition of the flowback and production waters is variable over time and the development of a tool that allows predicting this temporary variation would facilitate the necessary (Sovacool, 2014) improvement in risk management and monitoring;

Once the model has been developed, it is going to be applied to other families of organic compounds present in the return waters. To determinate the composition of the source term for the risk assessment, this work uses data released by the Marcellus Shale Coalition (Hayes database) in a report of the Gas Technology Institute, coming from 19 Marcellus hydraulic fractured wells (Hayes, 2009) from three sites in the northern half of West Virginia with the other 16 sites in Pennsylvania. 
Out of a total of 19 wells, this work focuses on those sites that have horizontal wells (Locations C, D, E, F, G, K and M in the Hayes report). The analyses carried out in produced water indicate that its chemical composition includes hydrocarbons, metals, NORM and other naturally occurring compounds. Each of these measurements were taken at different times, covering flowback and produced water. For this purpose, measures available at every given time point will be used: Day 0 - samples extracted from the supply water plus hydraulic fracturing additives, yet without sand. Days 1, 5, 14 - after having collected hydraulic fracturing chemicals samples, produced water at day 90 after completion was collected (Hayes, 2009).

Given the large number of compounds first analysed on the Hayes database, the elements were studied in detail in order to group them together by representative families. The process was as follows: according to the organic compounds data in flowback water from Hayes (Hayes, 2009), chemicals data with similar physicochemical and ecotoxicological properties were classified and grouped. Moreover, chemicals had to be filtered into a new intentional group whose $k_{o c}$ (soil organic carbon-water partitioning coefficient) value was quite different than other compounds in the same group, for example, benzene and TEX (toluene, ethylbenzene, xylene). Eight groups were settled in our research: acetophenone, benzene, phenol, TEX, TMB (1,2,4-trimethylbenzene, 1,3,5trimethylbenzene), R-Benzene (isopropylbenzene, N-butylbenzene, $\mathrm{N}$ propylbenzene, Sec-butylbenzene, P-isopropyltoluene), NAPH (naphthalene), and PAH-NAPH (Polycyclic aromatic hydrocarbons - naphthalene).

Hayes, 2009 reported that approximately $96 \%$ of VOCs in flowback water were found at non-detectable levels; among SVOCs, more than $98 \%$ of all determinations were at non-detectable levels, and $0.03 \%$ of these constituents were above $1 \mathrm{ppm}$. In order to conveniently perform the analysis the average concentration values were calculated for model fitting. We take into account the concentration of organic constituents in the same group coming from all horizontal wells (Locations C, D, E, $F, G, K$ and $M$ in the Hayes report).

The final average data calculated from the concentrations of the different compounds included in each group for all the horizontal wells can be seen in Table 3 . The value of day 0 corresponds to the injected water concentrations (Hayes, 2009). So, in some cases, the flowback water would be strongly influenced by this injected water.

Given the scarcity of temporal data, the TFRC model should be applied with caution. Although the experimental adjustment for the fast part of the transportation model (Eq. 11a) was adequate (days $0,1,5$ and 14) the purely empirical adjustment for the slow transportation part (Eq. 11b) was not feasible due to the insufficient available data. In Hayes, 2009 article only limited data (90th day) appeared associated with the slow-part behaviour of the TFRC model and it is impossible to fit the model in a univocal way.

Therefore, to estimate the predictive behaviour of VOCS and SVOCs, the $C_{t f \text { fast }}$ model (Eq. 11a) will be applied for fitting in the range of the first 14 days, with fast desorption. In order to obtain a first long-term predictive approximation to the slow part behaviour $\left(C_{t_{-} \text {slow }}\right.$ Eq. $\left.11 \mathrm{~b}\right)$ a $k_{\text {slow }}$ value based on representative equations will be calculated (Birdwell et al., 2007):

$k_{\text {slow }}=\frac{D_{0}}{\varphi_{e}^{-1 / 3} \cdot R_{d} \cdot l^{2}} ; R_{d}=1+\frac{\rho_{b}}{\varphi_{e}} \cdot K_{o c} \cdot f_{o c}$
For these calculations it will be necessary to use, on the one hand, the flow velocity obtained from the adjustment of the fast part as well as local geographic parameters $D_{0}, l, k_{o c}, f_{o c} \rho_{b}$ and $\phi_{e}$ based on local geophysical information (see Table 1 ). $C_{O_{-} \text {slow }}$ (see Eq. $11 \mathrm{~b}$ ) represents the initial chemical concentration present in the shale formation that is available for slow desorption and acts as a scaling factor. It can be determined in some cases by making use of the experimental concentration in 90th day. Monte-Carlo methods were used to propagate the uncertainty throughout the slow model calculation process. This allows obtaining a first long-term predictive approximation to the behaviour of the groups of compounds as well as the uncertainties associated with such behaviour.

\subsection{Fitting the model with fast-part transportation data}

Using the time evolution of the chemical concentrations makes it possible to reconstruct the transport coefficients for each element or group of elements by solving an inverse problem for equation (Eq. 11a). Starting from equation (Eq. 11a), with the unknown quantities $C_{0 f a s,} v / R_{d}$ and $k_{f a s t}$, we adjust these parameters so that the simulated evolution of concentrations fits into the experimental values using a least squares fitting method.

The data used for the adjustment was the mean value of concentrations for all the wells at every time point and for every considered chemical family. By observing the fitting data resulting curves in Fig. 5 , we found that, when fracturing began, dissolved organic chemicals were mobilized into lower concentration fluids. This was the reason why flowback water concentration value increased during the first days. The value of concentration in flowback water increases until reaching the curve peak, and then the concentration would decline because the dissolved chemicals are consumed on the first days.

The results of Fig. 5 allow observing three types of behaviours. A first case, which would include Acetophenone, Benzene, TEX, and TMB, consists of those compounds that, or are not present in the water that is injected or, if they are initially in the injected water, their concentrations are very low in comparison with the concentrations in the flowback waters. These compounds present a clear separation between the processes associated with rapid/slow desorption and the developed model is capable of making an adequate predictive estimate of their time evolution.

There is a second behaviour associated with the Phenol group or any other compound with high solubility. The 14 th-day concentration value of phenol was a little higher than 5th-day data, and value of $R^{2}$ indicates that the model does not adequately explain the experimental data. The reason is explained by the fact that Phenol was easily soluble in a higher temperature environment. That means that the result at the 14 th day was a combined $k_{\text {slow }}$ and $k_{\text {fast }}$ transportation behaviour. The existing data is not enough to make the fit in an adequate way because the fast and slow behaviours described by their respective equations cannot be applied separately.

Data for R-Benzene in the 1st and 5th days' data are under the analytical detection limits so it was not possible to carry out the fitting. Finally, we have the behaviour given by those groups of compounds, such as those of NAPH and PAH-NAPH, which have high concentrations in the injection water and, therefore, these values will affect the concentrations measured in the first days, especially those of the 1st. In

Table 3

Horizontal wells organic average concentration results.

\begin{tabular}{|c|c|c|c|c|c|c|c|c|}
\hline Time (day) & Acetophenone & Benzene & Phenol & TEX & TMB & R-Benzene & $\mathrm{NAPH}$ & PAH-NAPH \\
\hline 0 & 0.17 & 0.31 & 0 & 6.04 & 8.96 & 0 & 0.56 & 9.78 \\
\hline 1 & 2.55 & 41.61 & 7.52 & 63.31 & 5.07 & 0 & 0.35 & 1.38 \\
\hline 5 & 3.23 & 128.14 & 6.6 & 188.76 & 12.81 & 0.17 & 0 & 0.25 \\
\hline 14 & 1.13 & 71.28 & 7.43 & 146.48 & 6.78 & 0.38 & 0 & 0 \\
\hline 90 & 0.85 & 72.5 & 1.13 & 1292.5 & 245.0 & 32.5 & 0 & 6.18 \\
\hline
\end{tabular}



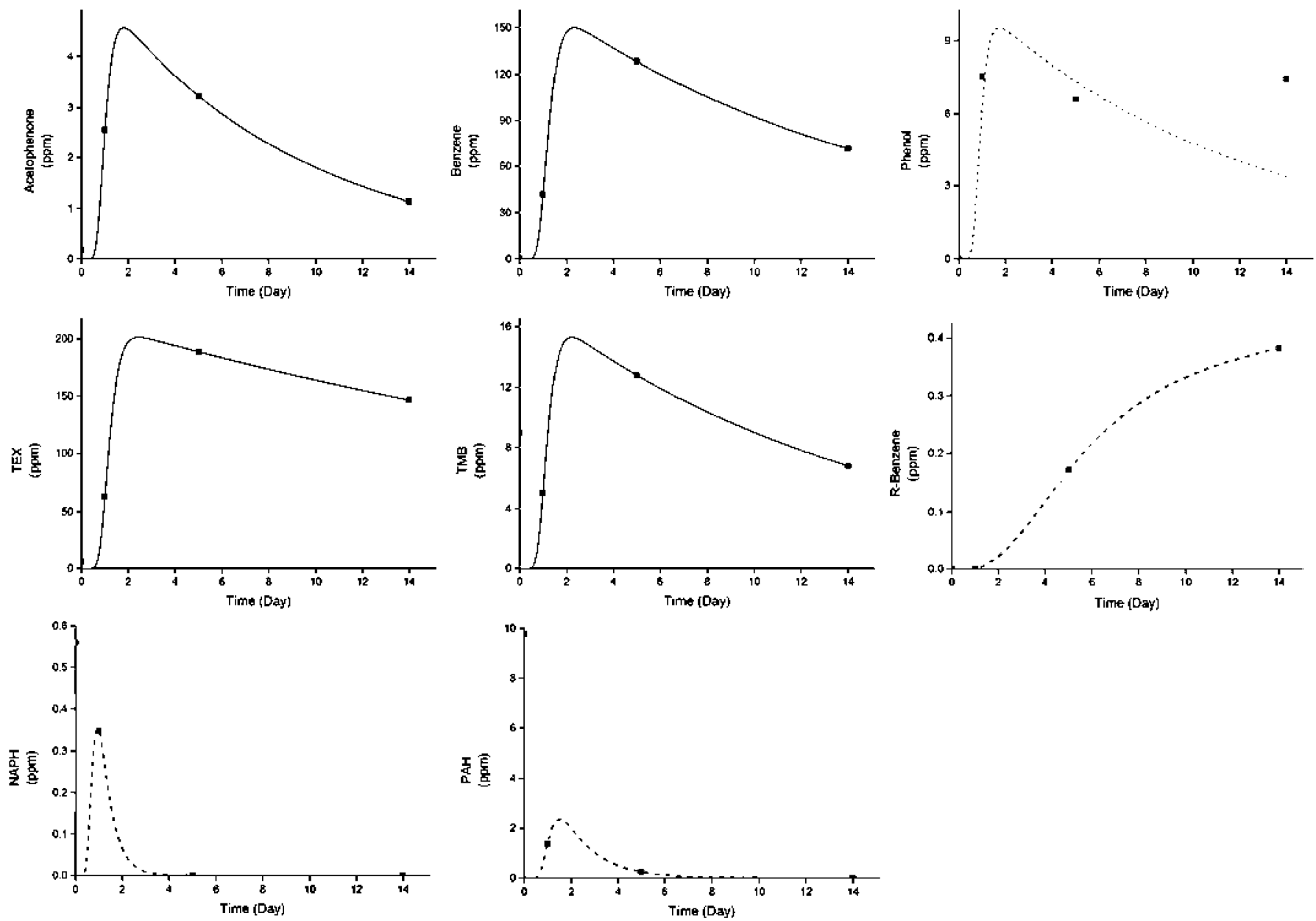

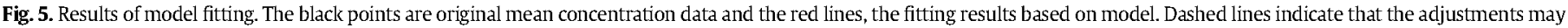
not be appropriate given the available data. (For interpretation of the references to colour in this figure legend, the reader is referted to the web version of this article.)

addition, the data of these groups as well as those of the R-Benzene, indicate that the associated desorption processes have very slow characteristic times since there are concentrations in the flowback waters starting from the measurement times of 14th and 90th days. The number of available data does not allow a good fit for the fast desorption behaviour. Because these compounds are extremely difficult to dissolve in water, there was insufficient temporal data in wastewater from Hayes (2009) for further analysis given that, in these cases, the curve peak would occur after that sampling time.

The theory has been proven by the resulting curves that show that the higher the $k_{o c}$ value was, the later the maximum concentration was reached. With the increase of property value of $k_{o c}$, the concentration curve peak would occur later. TMB and R-Benzene need more time to dissolve into the flowback fluid than Acetophenone or BETX compounds because of the $k_{o c}$ value.

Previously published articles have provided and proven the range number for $k_{\text {fast }}$ and the distribution of the kinetic rate constant values ranging from 0.01 to $50 \mathrm{~d}^{-1}$ for the fast scenario (Birdwell et al.,

Table 4

The results of model fitting into the analysis field.

\begin{tabular}{llllll}
\hline & Acetophenone & Benzene & Phenol & TEX & TMB \\
\hline$C_{0_{\text {fast }}(\mathrm{ppm})}$ & 5.79 & 177.50 & 11.27 & 217.32 & 18.24 \\
$v / R_{d}(\mathrm{~m} / \mathrm{d})$ & 2.97 & 2.43 & 3.24 & 2.54 & 2.54 \\
$k_{\text {fast }}\left(\mathrm{d}^{-1}\right)$ & 0.12 & 0.065 & 0.085 & 0.028 & 0.071 \\
$R^{2}$ & 0.98 & 0.99 & $\mathbf{- 0 . 4 1}$ & 0.99 & 0.99 \\
\hline
\end{tabular}

2007). For our fitting results, the rate $k_{\text {fast }}$ ranged from 0.02 to $2 \mathrm{~d}^{-1}$ (Table 4), and all of the fitting values were within the prediction range.

The purpose of hydraulic fracturing for shale gas is to create cracks by means of high-pressure fluid in sedimentary shale formation that could let hydrocarbons flow more freely. Oil and gas may be produced in this manner. Hydraulic conductivity is a measure of a material's capacity to transmit water. Generally, in a shale formation the value varies between $10^{-13}$ and $10^{-9} \mathrm{~m} / \mathrm{s}\left(3 \times 10^{-13}-3 \times 10^{-9} \mathrm{ft} / \mathrm{s}\right)$. Organic compounds' effective transport velocities depended on the retention factor $R_{d}$. This factor is inversely proportional to the organic carbon partition coefficient $k_{o c}$. The fitting result of $\boldsymbol{v}$ value ranged from $10^{-6}$ to $10^{-4} \mathrm{~m} / \mathrm{s}\left(3 \times 10^{-6}-3 \times 10^{-4} \mathrm{ft} / \mathrm{m}\right)(0.36-3.58 \mathrm{~m} / \mathrm{d}(0.11-1.1 \mathrm{ft} / \mathrm{d}))$ since the porosity was elevated by hydraulic fracturing operation in the shale formation.

The coefficient of determination $\left(R^{2}\right)$ was meant to define how close the sampling data fitted this modelling line. The determination coefficient value of compounds accounts for more than 0.98 (except for phenol), which means that our model could precisely describe the actual samples concentration change and dynamic transportation. The accurate model fitting obtained also allow concluding that, in this particular case, it is not necessary to introduce additional processes, such as biodegradation, to explain the system's behaviour.

\subsection{Estimating long-term (slow-part) transportation concentration}

The predicted concentration ratios in wastewater modified in Fig. 6the grey shaded area represent estimating concentration ratio curve in one confidence interval $(\sigma)$ range-covered a large part of the estimation 

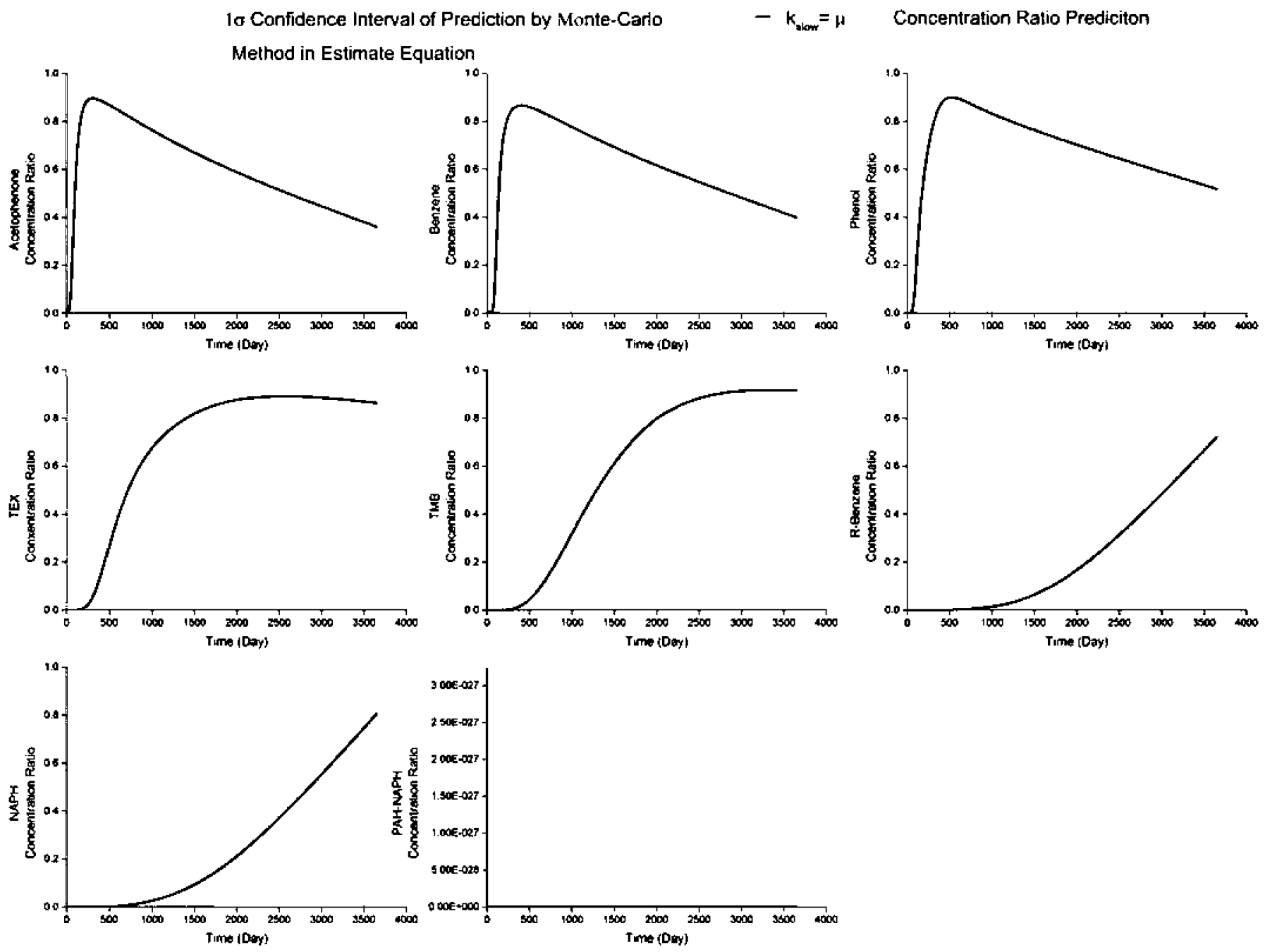

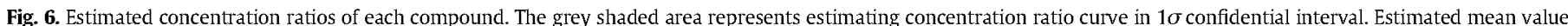
concentrations $(\mu)$ are represented by solid line in the figure (in PAH-NAPH this line is coincident with $x$-axis).

result, which could be representative if forecasting the curve tendency. $k_{\text {slow }}$ was the most important parameter in Eq. 12 . The mean $(\mu)$ value of $k_{\text {slow }}$ was used to estimate the concentration ratio in each analysed chemical, and the estimation results obtained are represented by the black solid line in Fig. 6 .

The bold values in Table 5 and black solid lines in Fig. 6 depict the estimated results of the concentration ratio calculated with average $k_{\text {slow }}$ value. As mentioned above, parameters $k_{\text {slow }}$ plays a decisive role in this predictive model for different compounds. The organic carbon partition coefficient $k_{o c}$ was the most important parameter for organic effective transport velocity. The higher the substances $k_{o c}$ value, the later the maximum concentration in estimation curve is reached. For instance, acetophenone is a water-soluble substance and $k_{o c}$ value is 52 . The estimated maximum ratio in 10 confidence interval would reach up to $90 \%$ compared with initial concentration within half a year after a fracturing operation. With the increase of the $k_{o c}$ value, the maximum concentration peak would appear later in time. For the benzene and phenol estimation curves, the peak would probably occur at the first year in this model estimation. On the other hand, for TEX and TMB chemicals, the maximum concentration for them all would appear at the 5 th year. The maximum concentrations under the estimated conditions for the right four compounds would appear at the 10 th year.

Table 5

Concentration ratio (calculated using Average $k_{\text {slow }}$ Value) (Maximum ratios are in Bold and Italics).

\begin{tabular}{|c|c|c|c|c|c|c|c|c|}
\hline Time (day) & Acetopheone & Benzene & Phenol & TEX & TMB & R-Benzene & NAPH & $\mathrm{PAH}-\mathrm{NAPH}$ \\
\hline 1 & 0 & 0 & 0 & 0 & 0 & 0 & 0 & 0 \\
\hline 5 & $3.74 \mathrm{E}-41$ & $1.10 \mathrm{E}-93$ & 0 & 0 & 0 & 0 & 0 & 0 \\
\hline 14 & $3.39 \mathrm{E}-13$ & $4.43 \mathrm{E}-16$ & 1.37E-15 & 0 & 0 & 0 & 0 & 0 \\
\hline 50 & $1.87 \mathrm{E}-02$ & $7.41 \mathrm{E}-03$ & $1.34 \mathrm{E}-04$ & $2.94 \mathrm{E}-27$ & $2.25 \mathrm{E}-47$ & 0 & 0 & 0 \\
\hline 90 & 4.42E-01 & $3.82 \mathrm{E}-03$ & $5.63 \mathrm{E}-02$ & 4.14E-14 & $2.93 \mathrm{E}-25$ & $5.18 \mathrm{E}-75$ & $5.60 \mathrm{E}-68$ & 0 \\
\hline 150 & $9.03 E-01$ & 8.14E-01 & $5.15 \mathrm{E}-01$ & $1.32 \mathrm{E}-07$ & 3.17E-14 & $4.68 \mathrm{E}-44$ & $7.80 \mathrm{E}-40$ & 0 \\
\hline 365 & $9.02 \mathrm{E}-01$ & $8.89 E-01$ & $9.57 E-01$ & $3.26 \mathrm{E}-02$ & $1.16 \mathrm{E}-04$ & $1.03 \mathrm{E}-16$ & $5.50 \mathrm{E}-15$ & 0 \\
\hline 730 & $8.15 \mathrm{E}-01$ & $8.24 \mathrm{E}-01$ & $8.64 \mathrm{E}-01$ & $6.56 \mathrm{E}-01$ & $1.04 \mathrm{E}-01$ & $2.82 \mathrm{E}-07$ & $1.96 \mathrm{E}-06$ & 0 \\
\hline 1825 & $6.00 \mathrm{E}-01$ & 6.32E-01 & 7.17E-01 & $9.29 E-01$ & $9.21 E-01$ & $5.10 \mathrm{E}-02$ & $9.38 \mathrm{E}-02$ & 0 \\
\hline 3650 & $3.60 \mathrm{E}-01$ & $3.98 \mathrm{E}-01$ & $5.18 \mathrm{E}-01$ & 8.64E-01 & $9.16 \mathrm{E}-01$ & $7.22 E-01$ & $8.06 E-01$ & $9.49 E-54$ \\
\hline
\end{tabular}


In the model developed, without considering biodegradation and chemical decay of some organic chemicals during the transportation process, the maximum concentration of organic compounds in produced water -shown in Table 5 in bold and italics- would reach up to $90 \%$ of the initial chemical concentration present in the shale formation that is available for slow desorption. For some low solubility substances such as R-Benzene, NAPH, or PAH-NAPH, ten years were not sufficient to reflect the whole transportation in the subsurface, therefore, estimation curves only represent the initial evolution of organic concentration and it was difficult to define when, and how much, the peak of maximum concentration would appear.

Our comprehensive model provides a new perspective to estimate prospective organic concentration ratio range tendency. The parameters of this model are associated with local geophysical information and physicochemical characteristics from organic substances. This means the model has strong adaptability to suit the different geological conditions and different organic compounds by tuning parameters. However, this model need to be improved with a large amount of data from different locations and with more frequent monitoring and covering longer times periods.

It is known that the leaking from storage tank may alter the transport channels in soil. In addition, the chemical interactions between tank wastewater and atmosphere and water system may lead to ecotoxicological risks (Chen et al., 2017; Jiang et al., 2014). Only understanding the local geo-information, organic leaking-processes, volatile and/or adsorption models, the environment risk assessment could be obtained faster and easier. All the above may contribute to optimize health risk assessment for local residents and provide knowledge to reduce the eco-toxicological risks from shale gas exploitations.

\section{Conclusions}

The core aim of this study is to determine a model meant to account for the whole transport process of organic compounds in a shale formation during the horizontal hydraulic fracturing operational life-cycle. A comprehensive model, combining organic matter transport dynamic model (including convection, diffusion, dispersion, desorption, adsorption and retention reaction in shale formation) and two-compartment first-order rate constant (TFRC) model in desorption profile, has been established.

In order to test and verify whether the model can be helpful in the risk assessment management by allowing the organic characterization of the source term and its time evolution, West Virginia and Pennsylvania Marcellus Shale data was chosen. There are two parameters $-k_{\text {fast }}$ and $k_{\text {slow }}$ - in our model to describe the physical-chemical desorption process, another one to characterize the advective-convective process - $v$ - and two last associated to the initial contaminants concentration available in the local environment to participate on desorption processes $-C_{0 \text { fast }}$ and $C_{0_{-} \text {slow. }}$. The transport model for the first 14 days is adequately explained with the processes described with the fast desorption. Two-thirds of the values of the criteria used to measure the goodness-of-fit are higher than 0.90 , and even some of them reach the 0.99 . This demonstrates that the implemented model describes adequately the transport processes of the analysed chemical substances to the flowback waters.

Based on the slow transportation part of numerical analysis and parameters, we are able to forecast concentration tendency of relevant chemicals. Under our analysis situation, Monte-Carlo methods succeeded in solving problems providing a probabilistic interpretation. On the basis of numerical ranges of hydraulic conductivity obtained from fitting results, local geographic parameters and model, the estimation mean value $(\mu)$ is made with one confidential interval $(\sigma)$ concentration ratio curve. The results from curves indicate that different organic compounds, with the higher $k_{o c}$ value, will have the last to reach peak concentration and this phenomenon can be explained by the retention factor theory during transportation. Finally, under our studied conditions, the maximum concentration in wastewater reaches up to $90 \%$ of the initial concentration available to slow desorption transport processes.

Nevertheless, there are some aspects that can be improved and the contamination transportation model can continue being updated to reflect a more realistic situation. During the transportation process, there is degradation and decay processes for organic chemicals although biocides are normally added to control bacterial growth in the geological formation and in surface production equipment. But these processes do not seem to be necessary in the fast desorption transportation given the good fit obtained. However, surely they may be necessary during the slow desorption transport phase that takes place over long periods of time, even reaching years. The lack of data during this period does not allow its evaluation. From the point of view of the risk assessment not considering these processes implies a conservative approach in favour of safety, as these would result in an expected decrease in the concentration of the analysed substances. From an operational point of view, the situation is the opposite since not considering them could lead to increased costs to meet regulations.

It would be interesting to apply this model in other sites with a greater number of time intervals monitoring covering especially the periods corresponding to slow desorption processes. It may contribute to have a more precise estimates of the expected concentrations in the return waters, which would be reflected in the preventive measures to be taken and therefore in the risks to the health of the local residents.

\section{Acknowledgments}

The research for this paper was financially supported by Ministerio de Economía y Competitividad, Spain [CTM2014-59828-R project]. We thank Fernando Recreo, from CIEMAT, for their assistance and contributions in developing the ideas presented here and Barry J. Katz for his suggestions that have improved this work considerably.

\section{References}

Akob, D.M., Cozzarelli, I.M., Dunlap, D.S., Rowan, E.L., Lorah, M.M., 2015. Organic and inorganic composition and microbiology of produced waters from Pennsylvania shale gas Wells. Appl. Geochem. 60 (September 2015), 116-125.

Balaba, R.S., Smart, R.B., 2012. Total arsenic and selenium analysis in Marcellus shale, high-salinity water, and hydrofracture flowback wastewater. Chemosphere 89 (11):1437-1442. https://doiorg/10.1016/j.chemosphere.2012.06.014.

Balashov, V.N., Engelder, T., Gu, X., Fantle, M.S., Brantley, S.L., 2015. A model describing flowback chemistry changes with time after Marcellus Shale hydraulic fracturing. AAPG Bull. 99 (1):143-154. https://doi.org/10.1306/06041413119.

Barnier, C., Ouvrard, S., Robin, C., Morel, J.L., 2014. Desorption kinetics of PAHs from aged industrial soils for availability assessment. Sci. Total Environ. 470-471:639-645. https://doi.org/10.1016/j.scitotenv.2013.10.032.

Bear, J., Verruijt, A., 1987. Modelling Groundwater Flow and Pollution. Publisher Springer Netherlands eBook ISBN 978-94-009-3379-8. https://doi.org/10.1007/978-94-0093379-8.

Birdwell, J., Cook, R.L., Thibodeaux, L.J., 2007. Desorption kinetics of hydrophobic organic chemicals from sediment to water: a review of data and models. Environ. Toxicol. Chem. 26 (3), 424-434

Bloomdahl, R., Abualfaraj, N., Olson, M., Gurian, P.L., 2014. Assessing worker exposure to inhaled volatile organic compounds from Marcellus Shale flowback pits. J. Nat. Gas Sci. Eng. 21:348-356. https://doi.org/10.1016/j.jngse.2014.08.018

Bunch, A.G., Perry, C.S., Abraham, L., Wikoff, D.S., Tachovsky, J.A., Hixon, J.G., Urban, J.D., Harris, M.A., Haws, L.C., 2014. Evaluation of impact of shale gas operations in the Barnett Shale region on volatile organic compounds in air and potential human health risks. Sci. Total Environ. 468-469:832-842. https://doi.org/10.1016/ j.scitotenv.2013.08.080.

Chen, S.S., Sun, Y., Tsang, D.C.W., Graham, N.J.D., Ok, Y.S., Feng, Y., Li, X.D., 2017. Potential impact of flowback water from hydraulic fracturing on agricultural soil quality: metal/metalloid bioaccessibility, Microtox bioassay, and enzyme activities. Sci. Total Environ. 579:1419-1426. https://doi.org/10.1016/j.scitotenv.2016.11.141.

Colborn, T., Kwiatkowski, C., Schultz, K., Bachran, M., 2011. Natural gas operations from a public health perspective. Hum. Ecol. Risk. Assess. 17, 1039-1056.

Cornelissen, G., Noort, P.C.M.V., Parsons, J.R., Govers, H.A.J., 1997. Temperature dependence of slow adsorption and desorption kinetics of organic compounds in sediments. Environ. Sci. Technol. 31 (2), 454-460 (1997).

Davies, R.J., Almond, S., Ward, R.S., Jackson, R.B., Adams, C., Worrall, F., Herringshaw, L.G., Gluyas, J.G., Whitehead, M.A. 2014. Oil and gas wells and their integrity: implications for shale and unconventional resource exploitation. Mar. Pet. Geol. 56, 239-254. 
Elhaddad, E., 2012. Sorption and Desorption Processes of Organic Contaminants on Carbonaceous Materials. (Dissertation zur Erlangung des akademischen Grades Doktor der Naturwissenschaften). Technischen Universität Darmstadt

Elliott, E.G., Ettinger, A.S., Leaderer, B.P., Bracken, M.B., Deziel, N.C., 2016. A systematic evaluation of chemicals in hydraulic-fracturing fluids and wastewater for reproductive and developmental toxicity. J. Expo. Sci. Environ. Epidemiol. May 2015:1-10. https://doi.org/10.1038/jes.2015.81.

EPA, 2013. Part 435 - Oil and gas extraction point source category. Title 40: Protection of Environment http://www.ecfr.gov/cgi-bin/text-idx?c=ecfr\&sid=b8fed7acf50261521a 80ea807ee5cf2a\&gn=div5\&view =text\&node $=40: 31.0 .1 .1 .11$ \&idno=40\#_top.

Gandossi, L., 2013. An overview of hydraulic fracturing and other formation stimulation technologies for shale gas production. European Commission Joint Research Centre Technical Reports https://doi.org/10.2790/99937.

Gdanski, R.D., Fulton, D.D., Johnson, B.J., 2010. Returns Matching Reveals New Tools for Fracture/Reservoir Evaluation. Paper SPE-133806-MS presented at Tight Gas Completions Conference, San Antonio, Texas, USA. https://oi.org/10.2118/133806-MS.

Hayes, T., 2009. Sampling and Analysis of Water Streams Associated with the Development of Marcellus Shale Gas. http://energyindepth.org/wp-content/uploads/marcellus/2012/11/MSCommission-Report.pdf.

He, C., Wang, X., Liu, W., Barbot, E., Vidic, R.D., 2014. Microfiltration in recycling of Marcellus Shale flowback water: Solids removal and potential fouling of polymeric microfiltration membranes. Journal of Membrane Science 462, 88-95 http:// doi.org/10.1016/j.memsci.2014.03.035.

Hoffman, A., Olsson, G., Lindström, A., 2014. Shale Gas and Hydraulic Fracturing: Framing the Water Issue. Report Nr. 34. SIWI, Stockholm.

Jackson, R.B., Vengosh, A., Darrah, T.H., Warner, N.R., Down, A., Poreda, R.J., Osborn, S.G., Zhao, K., Karr, J.D., 2013a. Increased stray gas abundance in a subset of drinking water wells near Marcellus shale gas extraction. Proc. Natl. Acad. Sci. U. S. A. 110 (28):11250-11255. https://oi.org/10.1073/pnas.1221635110.

Jackson, R.E., Gorody, A.W., Mayer, B., Roy, JW., Ryan, M.C., Van Stempvoort, D.R., 2013b. Groundwater protection and unconventional gas extraction: the critical need for field-based hydrogeological research. Groundwater 51 (4):488-510. https://doi.org/ 10.1111/gwat.12074.

Jiang, M., Hendrickson, C.T., VanBriesen, J.M., 2014. Life cycle water consumption and wastewater generation impacts of a marcellus shale gas well. Environ. Sci. Technol. 2014 (48):1911-1920. https://doi.org/10.1021/es4047654.

Jurus, W.J., Whitson, C.H., Golan, M., 2013. SPE 166439 Modelling Water Flow in Hydraulically-Fractured Shale Wells. Society of Petroleum Engineers. https:// doi.org/10.2118/166439-MS (2013, September 30).

Kan, A.T., Chen, W., Tomson, M.B., 2000. Desorption kinetics of neutral hydrophobic organic compounds from field-contaminated sediment. Environ. Pollut. 108 (2000), 81-89.

King, G.E., 2012. Hydraulic Fracturing 101: What Every Representative, Environmentalist Regulator, Reporter, Investor, University Researcher, Neighbor and Engineer Should Know About Estimating Frac Risk and Improving Frac Performance in Unconventional Gas and Oil Wells. S. Proceedings of the SPE Hydraulic Fracturing Technology Conference. ( 80 pp.). https://doi.org/10.2118/152596-MS

Kondash, A.J., Albright, E., Vengosh, A., 2017. Quantity of flowback and produced waters from unconventional oil and gas exploration. Sci. Total Environ. 574 (2017), 314-321.

Kravchenko, J., Darrah, T.H., Miller, R.K., Lyerly, H.K., Vengosh, A., 2014. A review of the health impacts of barium from natural and anthropogenic exposure. Environ. Geochem. Health 36 (4):797-814. https://doi.org/10.1007/s10653-014-9622-7.

Krupnick, A.J., Gordon, H., 2015. What experts say about the environmental risks of shale gas development. J. Agric. Resour. Econ. 44 (2), 106-119.

Krupnick, A.J., Gordon, H., Olmstead, S., 2013. Pathways to Dialogue: What the Experts Say about the Environmental Risks of Shale Gas Development. RFF Report. February 2013 Available on. http:/www.rff.org/files/sharepoint/Documents/RFF-RptPathwaystoDialogue_FullReport.pdf, Accessed date: 24 October 2017.

Kuwayama, Y., Roeshot, S., Krupnick, A., Richardson, N., Mares, J., 2015. Pits versus tanks: risks and mitigation options for on-site storage of wastewater from shale gas and tight oil development. Resources for the future. Discussion Paper RFF DP 15-53. December 2015.

Manger, E.G., 1963. Porosity and Bulk Density of Sedimentary Rocks. Geological Survery Bulletin 1144-E, 62.

McKenzie, L.M., Witter, R.Z., Newman, L.S., Adgate, J.L., 2012. Human health risk assessment of air emissions from development of unconventional natural gas resources. Sci. Total Environ. 424:79-87. https://doi.org/10.1016/j.scitotenv.2012.02.018.

Meng, Q., 2015. Spatial analysis of environment and population at risk of natural gas fracking in the state of Pennsylvania, USA. Sci. Total Environ. 515-516:198-206. https://doi.org/10.1016/j.scitotenv.2015.02.030
Molofsky, L.J., Connor, JA., Wylie, A.S., Wagner, T., Farhat, S.K., 2013. Evaluation of methane sources in groundwater in northeastern Pennsylvania. Groundwater 51 (3): 333-349. https://doi.org/10.1111/gwat.12056.

Nash, J.E., Sutcliffe, J.V., 1970. River flow forecasting through conceptual models, Part I - a discussion of principles. J. Hydrol. 10, 282-290 (1970)

Neuman, P., 1990. Universal scaling of hydraulic conductivities and dispersivities in geologic media. Water Resour. Res. 26 (8):1749-1758. https://doi.org/10.1029/ WR026i008p01749.

Osborn, S.G., Vengosh, A., Warner, N.R., Jackson, R.B., 2011. Methane contamination of drinking water accompanying gas-well drilling and hydraulic fracturing. Proc. Natl. Acad. Sci. U. S. A. 108 (20):8172-8176. https://doi.org/10.1073/pnas.1109270108.

Rahm, B.G., Bates, J.T., Bertoia, L.R., Galford, A.E., Yoxtheimer, D.A., Riha, S..., 2013. Wastewater management and Marcellus Shale gas development: trends, drivers, and planning implications. J. Environ. Manag. 120:105-113. https://doi.org/10.1016/ j.jenvman.2013.02.029.

Runkel, R.L., 1996. Solution of the advection-dispersion equation: continuous load of finite duration. J. Environ. Eng. 122 (9):830-832 (September 1996). https://doi.org/ $10.1061 / \% 28$ ASCE $\% 290733-9372 \% 281996 \% 29122 \% 3$ A9\%28830\% 29\#sthash.EN19Fe7L_dpuf.

Sauty, J.P., 1980. An analysis of hydrodispersive transfer in aquifers. Water Resour. Res. 16 (1):145-158. https://doi.org/10.1029/WR016i001p00145.

Schlegel, ME, McIntosh, JC, Petsch, S.T., Orem, W.H., Jones, EJ.P., Martini, AM, 2013. Extent and limits of biodegradation by in situ methanogenic consortia in shale and formation fluids. Appl. Geochem. 28 (January 2013):172-184. https://doi.org/10.1016/ j.apgeochem.2012.10.008.

Shan, C., Stephens, D.B., 1995. An analytical solution for vertical transport of volatile chemicals in the vadose zone. J. Contam. Hydrol. 18 (4):259-277. https://doi.org/ 10.1016/0169-7722(95)00011-J.

Sovacool, B.K., 2014. Cornucopia or curse? Reviewing the costs and benefits of shale gas hydraulic fracturing (fracking). Renew. Sust. Energ. Rev. 37, 249-264.

Stewart, B.W., 2015. Preface: geochemistry of unconventional shale gas from formation to extraction: petrogenesis, hydraulic fracturing, and environmental impacts. Appl. Geochem. 60, 1-2 (2015). (Guest Editors; Capo R. C. and Kirby C. S.).

Struchtemeyer, C.G., Morrison, M.D., Elshahed, M.S., 2012. A critical assessment of the efficacy of biocides used during the hydraulic fracturing process in shale natural gas wells. Int Biodeterior. Biodegrad. 71:15-21. https://oi.org/10.1016/ j.ibiod.2012.01.013.

Suárez, A.A., 2012. In: Al-Megren Dr., Hamid (Ed.), The Expansion of Unconventional Production of Natural Gas (Tight Gas, Gas Shale and Coal Bed Methane), Advances in Natural Gas Technology. InTech https://doi.org/10.5772/37404 Available from. https://www.intechopen.com/books/advances-in-natural-gas-technology/the-expansion-of-unconventional-production-of-natural-gas-tight-gas-gas-shale-and-coalbed-methane-.

Tan, J., 2014. Shale Gas Potential of the Major Marine Shale Formations in the Upper Yangtze. Genehmigte Dissertation Von der Fakultät VI - Planen Bauen Umwelt der Technischen Universität Berlin zur Erlangung des akademischen Grades eines Doktor der Naturwissenschaften.

U.S. EPA, 2015. Assessment of the Potential Impacts of Hydraulic Fracturing for Oil and Gas on Drinking Water Resources (External Review Draft). U.S. Environmental Protection Agency, Washington, DC (EPA/600/R-15/047, 2015).

Vengosh, A., Jackson, R.B., Warner, N., Darrah, T.H., Kondash, A., 2014. Risks to water resources from shale gas development and hydraulic fracturing in the United States. Environ. Sci. Technol. 16 (4):6838. https://doi.org/10.1021/es405118y.

Vidic, R.D., Brantley, S.L., Vandenbossche, J.M., Yoxtheimer, D., Abad, J.D., 2013. Impact of shale gas development on regional water quality. Science (New York, N.Y.) 340 (6134):1235009. https://doi.org/10.1126/science.1235009.

Viscusi, W.K. Hamilton, J.T. Dockins, P.C. 1997. Conservative versus mean risk assessments: implications for superfund policies. J. Environ. Econ. Manag. 34, 187-206.

Wamer, N.R., Christie, CA., Jackson, R.B., Vengosh, A., 2013. Impacts of shale gas wastewater disposal on water quality in Western Pennsylvania. Environ. Sci. Technol. 47 (20): 11849-11857. https://doi.org/10.1021/es402165b.

Willmot, C.J., 1981. On the validation of models. Phys. Geogr. 2 (2), 184-194 (1981).

Yost, E.E., Stanek, J., DeWoskin, R.S., Burgoon, L.D., 2016. Estimating the Potential Toxicity of Chemicals Associated with Hydraulic Fracturing Operations Using Quantitative Structure-Activity Relationship Modelling. Environ. Sci. Technol., acs.est.5b05327 https://doi.org/10.1021/acs.est.5b05327. 